\title{
AN EXPERIMENTAL STUDY OF THE MECHANISM OF ACTION OF KETAMINE ON THE CENTRAL NERVOUS SYSTEM
}

\author{
Davm H.W. Wong, M.B., B.S. \\ AND \\ Leonard C. Jenkins, M.D., C.M., F.R.C.P. (c)
}

\begin{abstract}
INTRODUCTION
THE CONCEPT OF KETAMINE as a dissociative anaesthetic was originally proposed by Corssen and Domino in $1966 .{ }^{1}$ Using acute cats which were immobilized, they implanted electrodes into various regions of the cortex, the thalamus and hippocampus, and observed the electroencephalographic (EEG) changes before and after intravenous injections of 2 to $4 \mathrm{mg} / \mathrm{kg}$ of ketamine. ${ }^{2}$ They found delta waves in the neocortical region and the thalamus, but theta-like activity in the hippocampus which represented the limbic system. Delta waves were seen in the somatosensory and association cortices, while the auditory and visual cortices were unaffected. Evoked potentials were markedly suppressed in all areas. They therefore proposed that ketamine blocked sensory input at the level of the thalamus and its perception at the association and somatosensory cortices, while leaving the limbic system and the specific sensory cortices unaffected.

This concept of differential action of ketamine on various parts of the central nervous system (i.e. depression of the neocortex and the thalamus with activation of the limbic system) was challenged by Kayama and Iwama in $1972 .^{3}$ They implanted electrodes in the sensorimotor cortex, visual cortex and hippocampus of cats and allowed two days for recovery before observing the EEG patterns following intravenous injections of ketamine $5 \mathrm{mg} / \mathrm{kg}$. Desynchronization of the EEG interrupted by bursts of spike discharges was observed in all the sites studied. They also found that ketamine markedly enhanced the evoked potentials of the sensorimotor and visual cortices. These findings were interpreted as indicating that ketamine stimulates the neocortex and hippocampus equally, and eventually induces seizure activity. Winters ${ }^{4}$ also produced evidence supporting these observations.
\end{abstract}

\section{Methods AND Results}

We used chronic cat preparations. Our approach differed from the previous workers in two other aspects:

1. Apart from systemic administrations, we also injected ketamine directly into the frontal cortex and subcortical sites.

2. We studied a total of 23 different subcortical sites (Table I).

From: Department of Anaesthesia, Faculty of Medicine, University of British Columbia.

Canad. Anaesth. Soc. J., vol. 21, no. 1, January 1974 
TABLE I

Central Nervous System Sites Injected with Ketamine

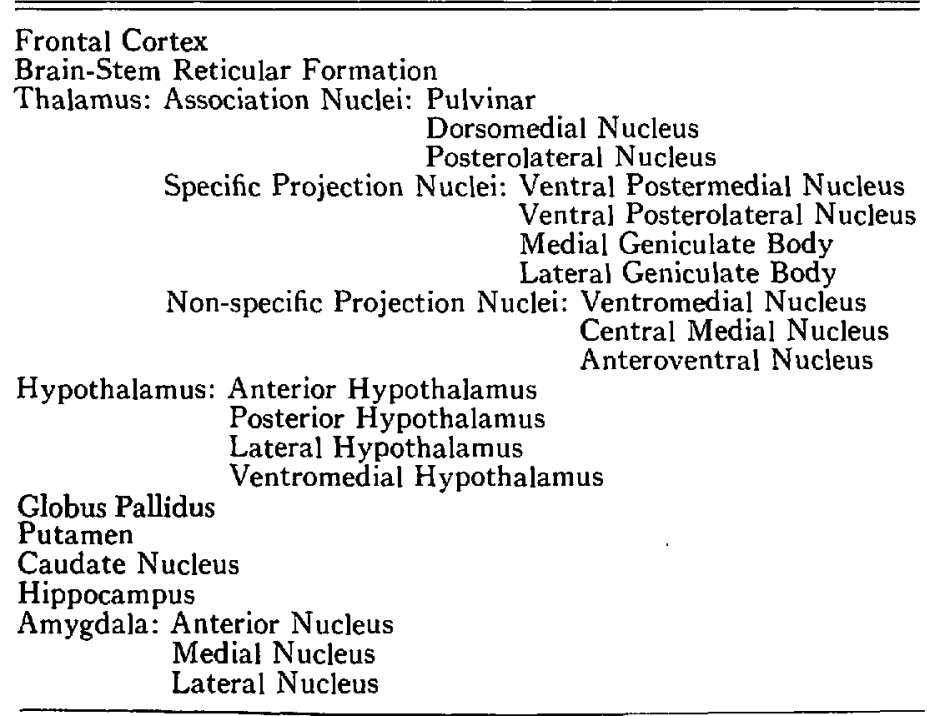

The cats were anaesthetized with intraperitoneal pentobarbitone $(35 \mathrm{mg} / \mathrm{kg}$ ) and mounted in a David Kopf stereotaxic apparatus. The sites implanted were according to the coordinates of Jasper. Each cat was implanted with four stainless steel screws resting on the frontal cortical dura. Subcortical structures were implanted with chemitrodes which consisted of cannulae fitted with recording wires to facilitate both injection of the drug and recording of electrical activity from each local site. Four of these chemitrodes, corresponding to two bilateral sites, were implanted into each cat.

The cats were allowed a minimum of two weeks for recovery before studies were undertaken and at least 48 hours between experiments. Three cats or more were used for each local site and a minimum of three injections were made at each site in each cat. Studies were done with the cat unrestrained in a viewing chamber with a one-way mirror.

\section{EFFECTS FROM Systemic Administration of Ketamine}

A control EEG recording (Figure 1) was made before each experiment. Sedation and analgesia were obtained with a dose of $2.5 \mathrm{mg} / \mathrm{kg}$ intramuscularly (IM). With increasing dosage, the effects came on earlier, more intensely, and more prolonged. With a dose of $40 \mathrm{mg} / \mathrm{kg} \mathrm{IM}$, spike discharges were apparent in the EEG within 45 seconds of injection, and this became full-blown at one minute (Figure 1). Respiration was markedly depressed. Spike discharges were still evident at the end of seven hours, and ataxia persisted for another three hours.

The optimal dose to produce consistent and reproducible behavioural and EEG changes was $10 \mathrm{mg} / \mathrm{kg} \mathrm{IM}$. This dose corresponds closely to the clinical dose used in man. All cats were studied following systemic administration of this dose before studies with local injections were undertaken. 
EFFECTS OF KETAMINE ON THE EEG

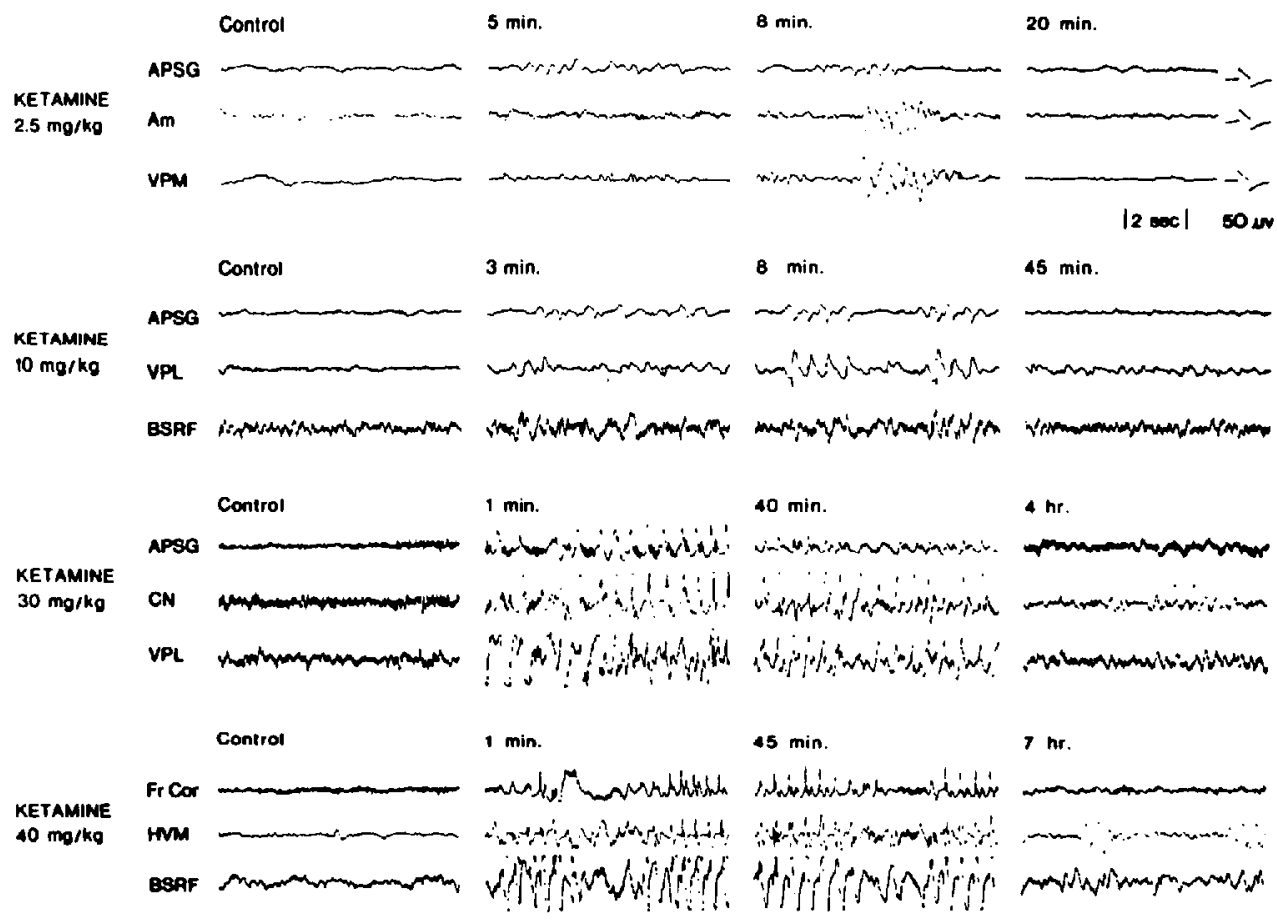

Figure 1. Effects of increasing intramuscular doses of ketamine on the EEG in the cat. APSG, anterior-posterior sigmoid gyrus; Am, amygdala; VPM, ventral posteromedial nucleus of thalamus; VPL, ventral posterolateral nucleus of thalamus; BSRF, brain-stem reticular formation; CN, caudate nucleus; Fr Cor, frontal cortical chemitrode; HVM, ventromedial hypothalamus. Only unilateral tracings of each site are shown.

Two minutes after IM administration of this dose, the cat began to sit still and lower the head, and spike discharges appeared in the EEG (Figure 2). In another minute, it lay quietly with eyes wide open, saliva dripping from the mouth, and occasional licking movements were made. Auditory, visual or noxious stimuli failed to elicit any behavioural or electrical response. The EEG at this stage showed bursts of high voltage slow frequency hypersynchronous spike discharges, alternating with low voltage fast frequency desynchronous activity (Figure 2). This pattern was apparent in all the sites studied (see also Figure 5). These findings differ from Corssen's original observations which showed selective activity on the C.N.S. ${ }^{2}$ This pattern persisted for 30 to 45 minutes. Even when the EEG had returned to the control pattern and when the cat was responding to various stimuli, marked ataxia persisted for another two hours.

\section{Effects from Direct Local (C.N.S.) Administration of Ketamine}

Our local injection studies involved injections of $10 \mu \mathrm{l}$ of the 5 per cent ketamine solution into each local site, a total of one milligram into the corresponding right and left chemitrodes. Using this approach, we were able to obtain 


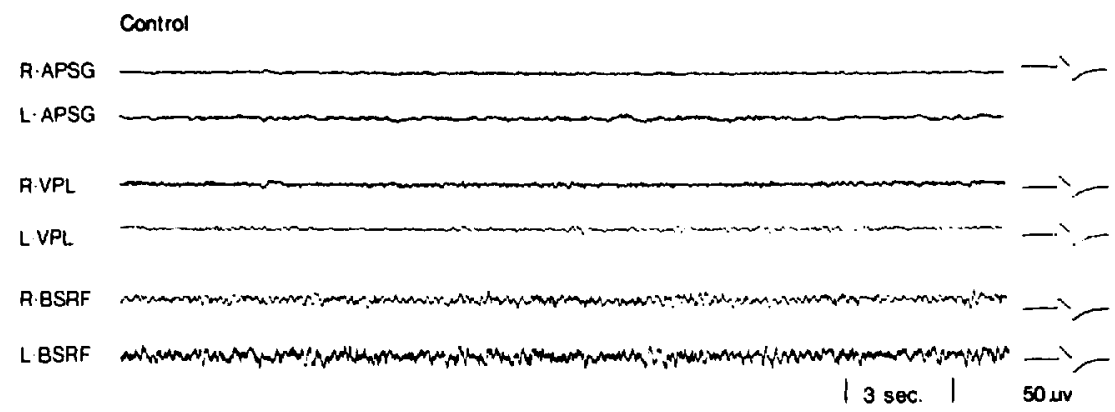

9 minutes after injection

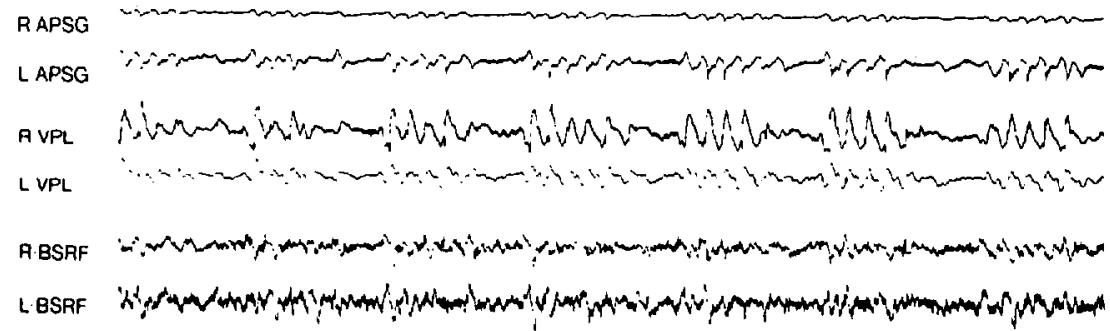

35 minutes after injection

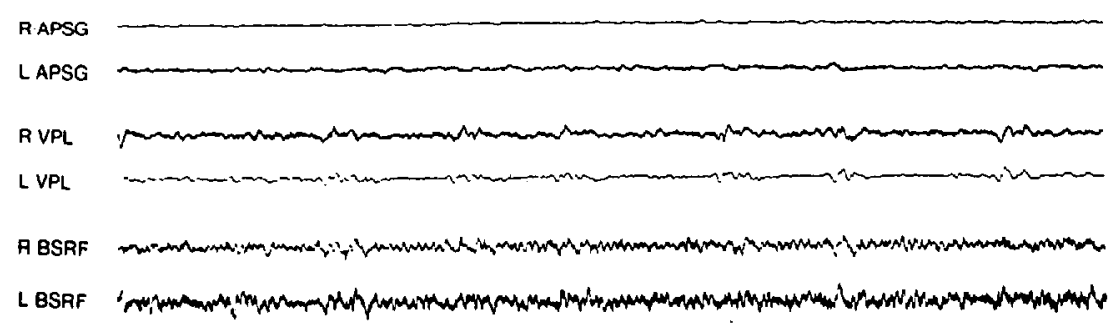

Ficure 2. Typical patterns of systematic ketamine $(10 \mathrm{mg} / \mathrm{kg}$ IM) anaesthesia in the cat. APSG, anterior-posterior sigmoid gyrus; VPL, ventral posterolateral nucleus of thalamus; BRSF, brain-stem reticular formation; $R$, right; $L$, left.

more direct information as to the sites in the C.N.S. responsible for some of the clinical manifestations of ketamine anaesthesia.

Sedation and analgesia: Varying degrees of sedation and analgesia were obtained from direct injections of ketamine into the anterior, posterior and lateral hypothalamus (Figure 3). These were obvious within one minute of injection. A previously alert cat would quietly settle down and would not move for 10 to 20 minutes. The eyes might or might not be open. While during the control period, pin-prick of the paws would make the cat jump, the same stimulus during the period of sedation would produce either a reduced response or none at all. In some experiments, these effects were produced even with unilateral injections.

The EEG pattern at the injected sites was variable from experiment to ex- 


\section{KETAMINE IN LATERAL hYPOTHALAMLS (BILATERALLY)}
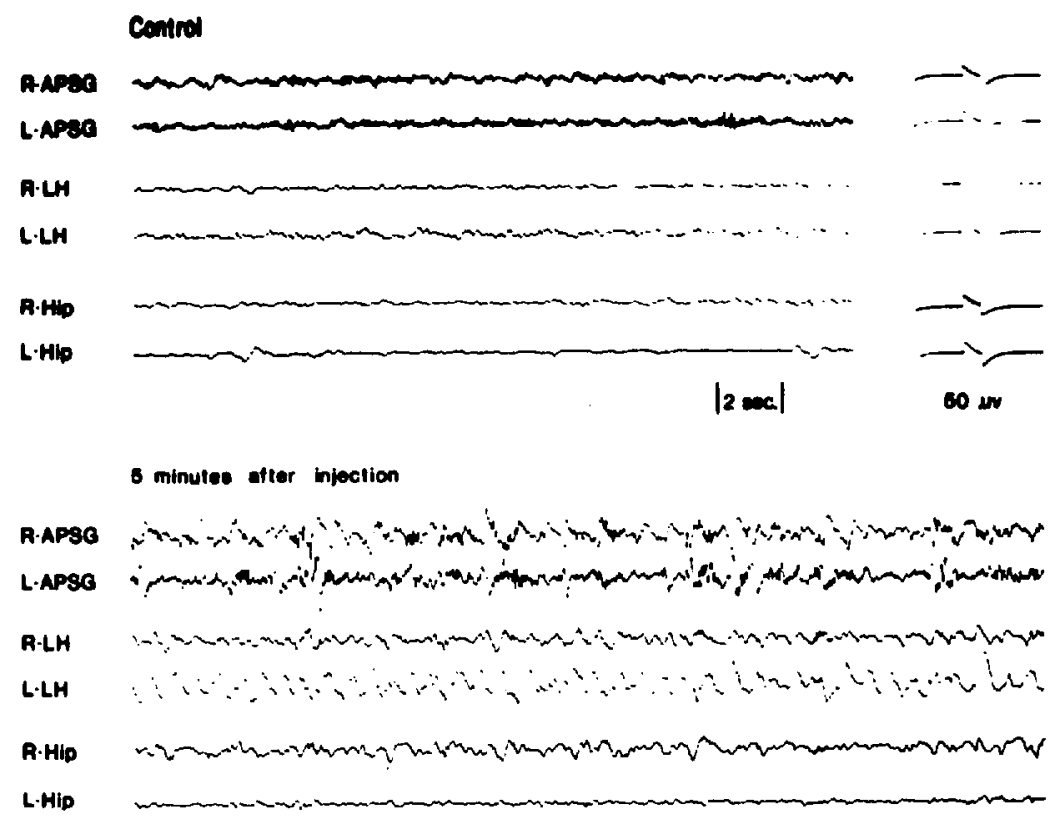

20 minutea alter injoction

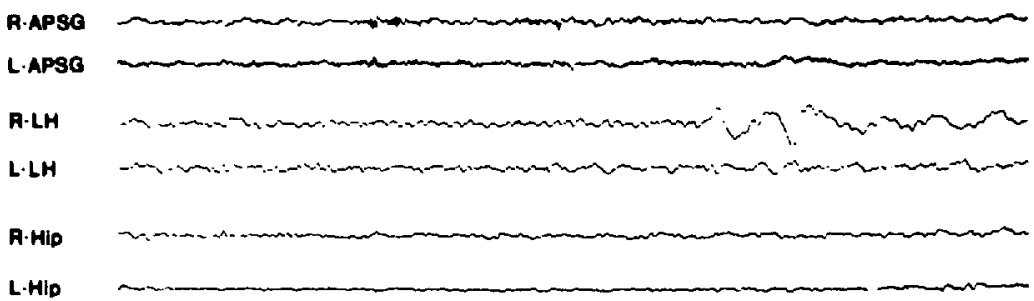

FIGURE 3. Effects of direct bilaterial ketamine injections into the lateral hypothalamus. Note the spike discharges induced in the frontal cortical sites. These were associated with marked sedation and analgesia in the cat. APSG, anterior-posterior sigmoid gyrus; LH, lateral hypothalamus; Hip, hippocampus; $R$, right; $L$, left.

periment, even in the same cat. Sometimes there was no change from the control pattern; at other times slow frequency and higher voltage waves were seen; and occasionally a few spike discharges were obvious. However, frontal cortical spike discharges were evident in the experiments where marked sedation was produced (Figure 3). These cortical spike discharges were identical to those obtained from systemic administration of ketamine.

The ventral medial nucleus of the hypothalamus, unlike the anterior, posterior or the lateral hypothalamus, did not differ from the control.

Catatonia: Catatonia was produced by injections of ketamine into the globus pallidus, and sometimes also the caudate nucleus. The cat stood with head raised, 
neck extended and eyes wide-open in a fixed stare. The same posture was maintained for periods of one to three minutes. These recurred once or twice within the first 15 minutes following injections. Between periods of this statue-like posture, the cat did not appear to be sedated and responded to stimuli. Pin-pricks even during the periods of catatonia could provoke response of withdrawal, but the animal rapidly resumed the original posture.

The EEG correlates varied from cat to cat, and from one experiment to another. Some did not show any change from the control, while others had runs of slow frequency and high voltage activity. The pattern did not appear to correlate well with the animal's behaviour.

Injections of ketamine into the putamen did not produce similar effects and the cats did not show deviation from the control both behaviourally and electrically.

Salivation: Salivation of moderate to marked degree has been observed in experiments where ketamine was injected into the hypothalamus, the thalamus, globus pallidus and caudate nucleus. The finding was unpredictable, and was not always reproducible in the next experiment even in the same cat. In some experiments the saliva was profuse and thick, and appeared as a continuous column stretching from the mouth to the floor while the cat was standing. Salivation was not associated with any fixed pattern of behavioural or EEG changes.

Restlessness: Direct injections of ketamine into the lateral geniculate body (specific visual projection nucleus) produced moderate restlessness for 10 to 15 minutes. The cats chased their own tails, avoided moving objects, and at times banged their heads on the wall. The restlessness was intensified by stimulation with light flashes. Apart from artefacts from movements of the cat, the EEG correlates did not show any change from the control.

Marked restlessness lasting 5 to 15 minutes was produced in 14 experiments with brain-stem reticular formation. (BSRF) injections. This was manifested as continual movements of the head and body, walking circles in the chamber, trying to knock the cable off, scratching the chamber wall, and crying aloud. Thereafter the cat remained alert for 30 to 60 minutes, responding to sound and light by moving the head and body. At no time was there analgesia to pin-prick. In one of the four cats, the injections produced intermittent generalized clonic convulsions for three minutes in two experiments (Figure 4). These appeared first as twitching of the head and neck and fore-limbs, and rapidly spread to the body and hind-limbs. Respiration was slow and deep for the following five minutes. However, subsequent experiments on this cat failed to produce convulsions, although marked restlessness was still present.

Slow frequency and high voltage waves amounting to spike discharges were consistently present in the EEG correlates of BSRF injections. In the cat that showed convulsions, bursts of spike discharges were apparent in all the sites implanted (BSRF, lateral hypothalamus and frontal cortex) (Figure 4). At the end of the convulsions, the frontal cortical discharges disappeared. The enhanced activity in the BSRF, however, remained for a few minutes more.

Other sites: No consistent behavioural or electrical change from the control was 
KETAMINE IN BSRF (BILATERALLY)
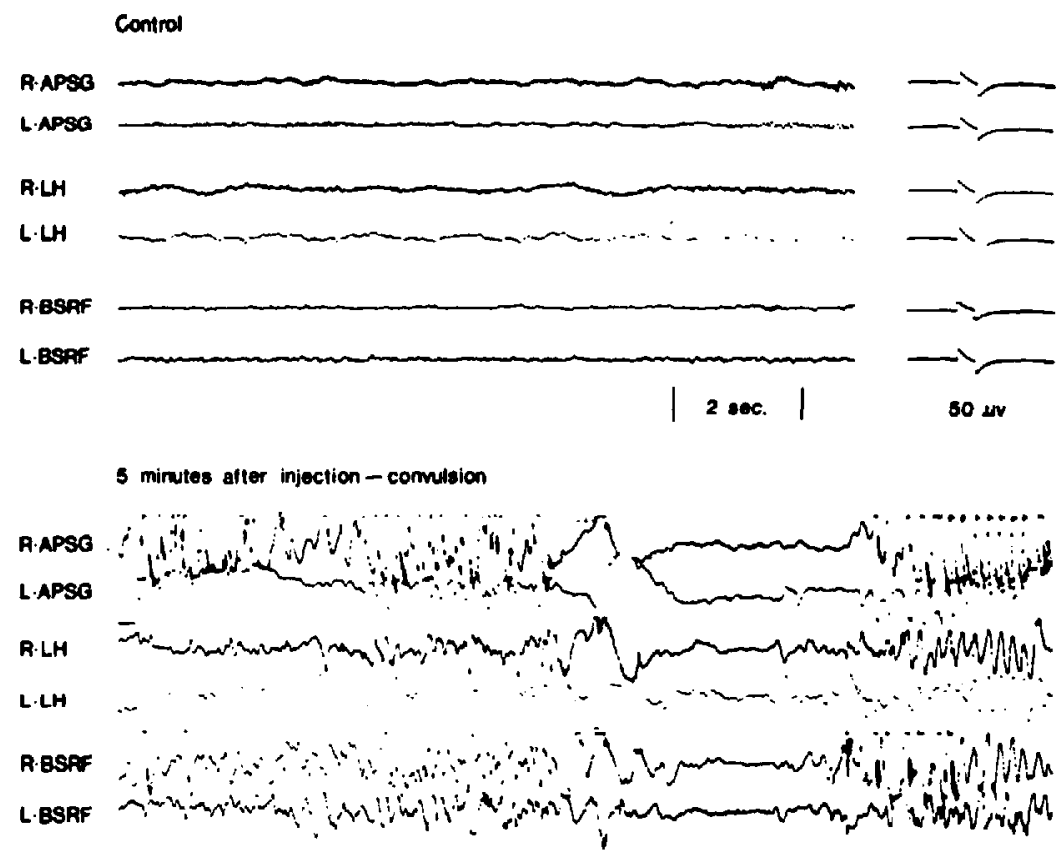

30 minutes alter injection

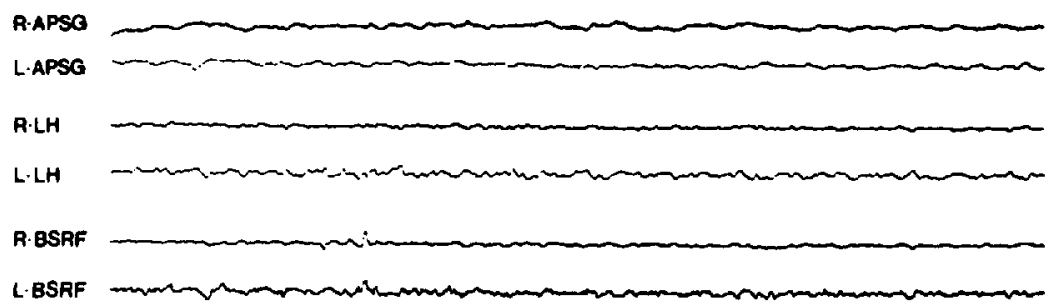

Figure 4. Effects of direct local ketamine injections into the brain-stem reticular formation. The tracings taken at 5 minutes after injection were taken at the peak of convulsions. The characteristic bursts of spike discharges alternating with desynchronized activity were present even during convulsions. Note also that this pattern was present in all sites. APSG, anteriorposterior sigmoid gyrus; LH, lateral hypothalamus; BSRF, brain-stem reticular formation; $\mathrm{R}$, right; $\mathrm{L}$, left.

observed from local injections of ketamine into the frontal cortex, the various nuclei of the thalamus (except the lateral geniculate body), the hippocampus and the amygdala.

Identical volumes of isotonic saline adjusted to the same $\mathrm{pH}$ as the 5 per cent ketamine preparation did not alter the control behavioural or electrical pattern on direct application.

Table II and Figure 5 summarize the results. 
TABLE II

EFFects of Systemic InJections of Ketamine and of Direct Injections into the Central Nervous System

\begin{tabular}{|c|c|c|}
\hline Effect & Site of Ketamine Injection & EEG Correlates \\
\hline $\begin{array}{l}\text { Sedation, analgesia } \\
\text { catatonia, salivation, } \\
\text { ataxia }\end{array}$ & Systemic (I/M) & $\begin{array}{l}\text { Spike discharges alternating } \\
\text { with desynchronized low } \\
\text { voltage! fast frequency waves } \\
\text { in all sites }\end{array}$ \\
\hline Sedation, analgesia & $\begin{array}{l}\text { Anterior, posterior and } \\
\text { lateral hypothalamus }\end{array}$ & $\begin{array}{l}\text { Spike discharges in frontal } \\
\text { cortex, but inconsistent at } \\
\text { site of injection }\end{array}$ \\
\hline Catatonia & Globus pallidus & $\begin{array}{l}\text { Variable: no change or slow } \\
\text { frequency, high voltage waves }\end{array}$ \\
\hline Salivation & $\begin{array}{l}\text { Variable and inconsistent: } \\
\text { hypothalamus, globus } \\
\text { pallidus, caudate nucleus }\end{array}$ & $\begin{array}{l}\text { No fixed pattern: usually no } \\
\text { change from control }\end{array}$ \\
\hline $\begin{array}{l}\text { Restlessness } \\
\text { Marked restlessness } \\
\pm \text { convulsions }\end{array}$ & $\begin{array}{l}\text { Lateral geniculate body } \\
\text { Brain-stem reticular } \\
\text { formation }\end{array}$ & $\begin{array}{l}\text { No change from control } \\
\text { Spike discharges in BSRF: } \\
\text { also in cortex during con- } \\
\text { vulsions }\end{array}$ \\
\hline
\end{tabular}

\section{Discussion}

Our observations on the EEG changes following systemic administration of ketamine suggest that all parts of the C.N.S. are excited. These are in agreement with Kayama and Iwama ${ }^{3}$ and Winters. ${ }^{4}$ The appearance of excitatory patterns in the frontal cortex following direct hypothalamic injections, and in the frontal cortex and hypothalamus following direct BSRF injections would suggest, however, that the excitatory phenomenon, at least in some sites, may be secondary to stimulation of other C.N.S. sites, and that relay pathways may be involved. Our study does not support a differential action of ketamine on various C.N.S. sites following systemic administration; neither does it support the concept that ketamine stimulates all parts of the C.N.S. directly. Thus the mechanism appears to be much more complex than was originally thought. However, whether through a direct or an indirect mechanism, the final effect following its systemic administration is excitation of all C.N.S. sites. Furthermore, Dawson ${ }^{5}$ has shown that ketamine increased cerebral oxygen consumption (suggesting increased cerebral activity) and that this could be prevented by prior treatment with thiopentone.

Our observations would suggest that the sedative and analgesic effects of ketamine are due to its action on the hypothalamic nuclei. It is interesting that these effects, produced by direct hypothalamic injections, are associated with spike discharges in the frontal cortex rather than at the site of injection. The hypothalamic-cortical conduction pathways are probably involved. This leads us to believe that the loss of consciousness and possibly the analgesia produced by ketamine is due to induction of EEG seizures in the cortex as in petit mal epilepsy. Furthermore, failure to produce an anaesthetic state in patients with cerebral cortical pathology has been recently reported.6,7

Our current studies also suggest that the haemodynamic effects of ketamine 


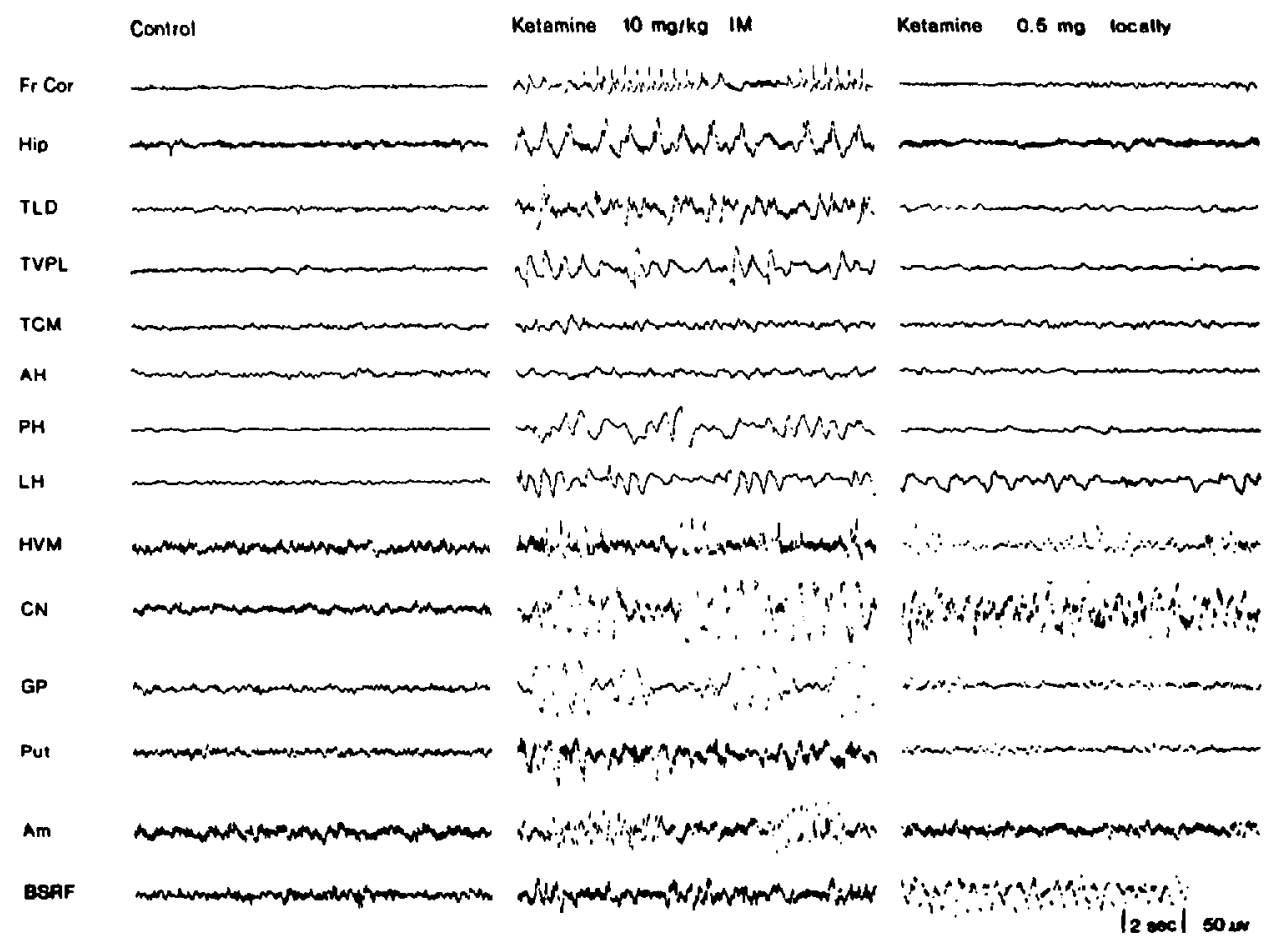

Figune 5. Comparison of EEG patterns from systemic and local ketamine injections in the cat. The EEG patterns from direct ketamine injections into the lateral hypothalamus, ventromedial hypothalamus and caudate nucleus were inconsistent; tracings showing a change from the control pattern are shown here. The change in electrical response from local BSRF injections, however, was consistent. Fr Cor, frontal cortical chemitrode; Hip, hippacampus; TLD, dorsolateral nucleus of thalamus; TVPL, ventral posterolateral nucleus of thalamus; TCM, central medial nucleus of thalamus; $\mathrm{AH}$, anterior hypothalamus; $\mathrm{PH}$, posterior hypothalamus; LH, lateral hypothalamus; HVM, ventromedial hypothalamus; $C N$, caudate nucleus; GP, globus pallidus; Put, putamen; Am, amygdala; BSRF, brain-stem reticular formation.

such as increase in cardiac output, arterial blood pressure and heart rate might be effects of excitation of the central nervous system.

We have produced direct evidence that the motor effects of ketamine administration are at least in part due to stimulation of the globus pallidus. However, we have not yet localized the site responsible for the observed salivation. This has been produced by injections into a number of C.N.S. sites, and excitation from these sites may be relayed to a common site as yet unidentified.

Preliminary observations suggest that some of the hallucinations may be due to stimulation of the thalamus, and particularly the visual projection nuclei.

Our study indeed supports Winters' concept of ketamine as a "stage II anaesthetic," producing cataleptoid C.N.S. excitation with catatonia and hallucination and at the same time causing a reduction in responsiveness to stimuli and loss of memory."

Direct injection of ketamine into the BSRF produced restlessness with an ex- 
citatory pattern in the EEG. In the cat, where convulsion was produced, spike discharges were also evident in the frontal cortex and these were identical to those observed following systemic ketamine.

There is thus need for re-evaluation of the use of this drug in young children with developing nervous system tissue, and in diagnostic procedures involving neurological problems. Its ability to produce seizure pattern in the EEG suggests caution in its use in patients with convulsive disorders. ${ }^{8}$ Indeed, Walker ${ }^{9}$ has reported a case where ketamine repeatedly precipitated convulsions in a child with a history of epilepsy.

\section{SUMMary}

The present study of the mechanism of action of ketamine on the central nervous system was carried out by the use of chronically implanted chemitrodes in a wide variety of C.N.S. sites in the cat.

Systemic injections of ketamine were found to stimulate all parts of the C.N.S. studied, directly or indirectly, producing a characteristic pattern of high voltage, slow frequency spike discharges alternating with low voltage, fast frequency desynchronized activity. This differs from Corrsen's original observations of selective action and his concept of dissociative anaesthesia.

Anterior, posterior and lateral hypothalamic injections produced varying degrees of sedation and analgesia associated with cortical spike discharges; globus pallidus injections produced catatonia; lateral geniculate body injections produced restlessness which was intensified by stimulation with light flashes; BSRF injections produced restlessness and even convulsions; and injections into the frontal cortex, the various other nuclei of the thalamus, hippocampus and amygdala did not produce any consistent response.

An explanation of the various manifestations of ketamine anaesthesia is proposed, based on these observations. We believe that the unconsciousness produced is secondary to the induced cortical EEG seizures. This suggests the need for caution in the use of ketamine in convulsive disorders and in your patients with a developing central nervous system.

\section{RÉSUMÉ}

La présente étude sur le mécanisme d'action de la kétamine sur le système nerveux central a été faite grâce à l'emploi de chimitrodes implantées chroniquement dans une grande variété de sites du système nerveux central de chats.

Des injections systémiques de kétamine, d'après nos résultats, stimulent toutes les parties du S.N.C. étudiées soit directement, soit indirectement; ce produit provoque un tracé à haut voltage, des influx à fréquence lente alternant avec un bas voltage et une fréquence rapide d'activité asynchrone. Ceci est différent des observations originales de Corrsen d'action sélective et de son concept d'anesthésie dissociative.

Des injections hypothalamiques antérieures, postérieures et latérales ont produit divers degrés de sédation et d’analgésie associées à des influx corticaux; des 
injections dans le globus pallidus ont produit de la catatonie; des injections dans le corps géniculé latéral ont produit de l'agitation qui s'est aggravée par la stimulation d'éclairs lumineux; des injections dans le B S R F ont produit de l'agitation, et même des convulsions; des injections dans le cortex frontal, les divers autres noyaux du thalamus, de l'hyppocampe et des amygdales n'ont produit aucune réponse soutenue.

A la suite de ces observations, nous offrons une explication des diverses manifestations de l'anesthésie à la kétamine. Nous croyons que l'inconscience produite est secondaire aux convulsions corticales électro-encéphalographiques produites. A ce compte-là, il s'impose d'être prudent lors de l'usage de la kétamine dans les cas de désordres convulsifs et chez les jeunes malades dont le système nerveux se développe.

\section{ACKNOWLEDGMENTS}

This work was in part financed by grants-in-aid from the Burroughs Wellcome Company (Canada) and Poulenc Limited of Montreal. Ketamine (Ketalar ${ }^{\circledR}$ ) was supplied by Parke-Davis.

\section{REFERENCES}

1. Conssen, G. \& Domino, E.F. Dissociative anesthesia: further pharmacologic studies and first clinical experience with the phencyclidine derivative CI-581. Anesthesia and Analgesia (Cleveland) 45: 29-40 (1966).

2. Corssen, G., Miyasaka, M., \& Domino, E.F. Changing concepts in pain control during surgery: dissociative anesthesia with CI-581: a progress report. Anesthesia and Analgesia (Cleveland) 47: 746-759 (1968).

3. KaYAMA, Y. \& Iwama, K. The EEG, evoked potentials, and single-unit activity during ketamine anesthesia in cats. Anesthesiology 36: 316-328 (1972).

4. Wintens, W.D. Epilepsy or anesthesia with ketamine (editorial view). Anesthesiology 36: $309-312$ (1972).

5. Dawson, B., Michenfelder, J.D., \& Theye, R.A. Effects of ketamine on canine cerebral blood flow and metabolism: modification by prior administration of thiopental. Anesthesia and Analgesia (Cleveland) 50:443-447 (1971).

6. DruRY, W.L. \& CLARK, L.C. Ketamine failure in acute brain injury: a case report. Anesthesia and Analgesia (Cleveland) 49: 859-861 (1970).

7. Janis, K.M. \& Wrught, W. Failure to produce analgesia with ketamine in two patients with cortical disease. Anesthesiology 36: 405-406 (1972).

8. Dancer, P. Ketamine in der padiatrischen chirurgie, In Kreuscher H. (Ed.). Anaesthesiology and Resuscitatopm 40: Ketamine, p. 222, New York, Springer.

9. WALKER, A.K.Y. Intramuscular ketamine in a developing country: experience in the British Solomon Islands. Anaesthesia 27: 408-414 (1972). 